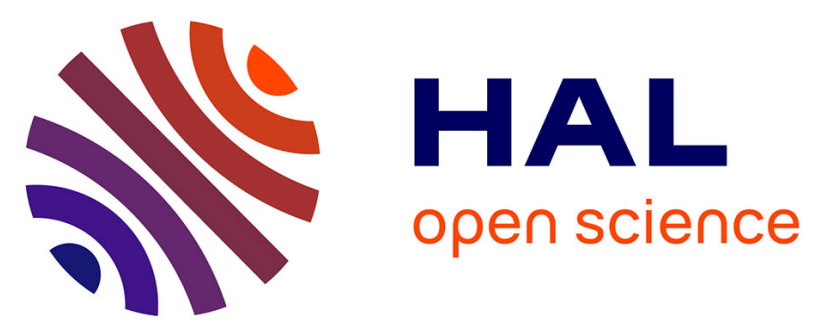

\title{
The Oxygen Isotope Compositions of Large Numbers of Small Cosmic Spherules: Implications for Their Sources and the Isotopic Composition of the Upper Atmosphere
}

N. G Rudraswami, Matthew J Genge, Yves Marrocchi, Johan Villeneuve, S. Taylor

\section{- To cite this version:}

N. G Rudraswami, Matthew J Genge, Yves Marrocchi, Johan Villeneuve, S. Taylor. The Oxygen Isotope Compositions of Large Numbers of Small Cosmic Spherules: Implications for Their Sources and the Isotopic Composition of the Upper Atmosphere. Journal of Geophysical Research. Planets, 2020, 125 (10), 10.1029/2020JE006414 . hal-03009464

\section{HAL Id: hal-03009464 \\ https://hal.univ-lorraine.fr/hal-03009464}

Submitted on 17 Nov 2020

HAL is a multi-disciplinary open access archive for the deposit and dissemination of scientific research documents, whether they are published or not. The documents may come from teaching and research institutions in France or abroad, or from public or private research centers.
L'archive ouverte pluridisciplinaire HAL, est destinée au dépôt et à la diffusion de documents scientifiques de niveau recherche, publiés ou non, émanant des établissements d'enseignement et de recherche français ou étrangers, des laboratoires publics ou privés. 
Title:

The oxygen isotope compositions of large numbers of small cosmic spherules:

Implications for their sources and the isotopic composition of the upper atmosphere

N. G. Rudraswami ${ }^{1}$, Matthew J. Genge ${ }^{2}$, Yves Marrocchi $^{3}$, Johan Villeneuve $^{3}$, S. Taylor ${ }^{4}$

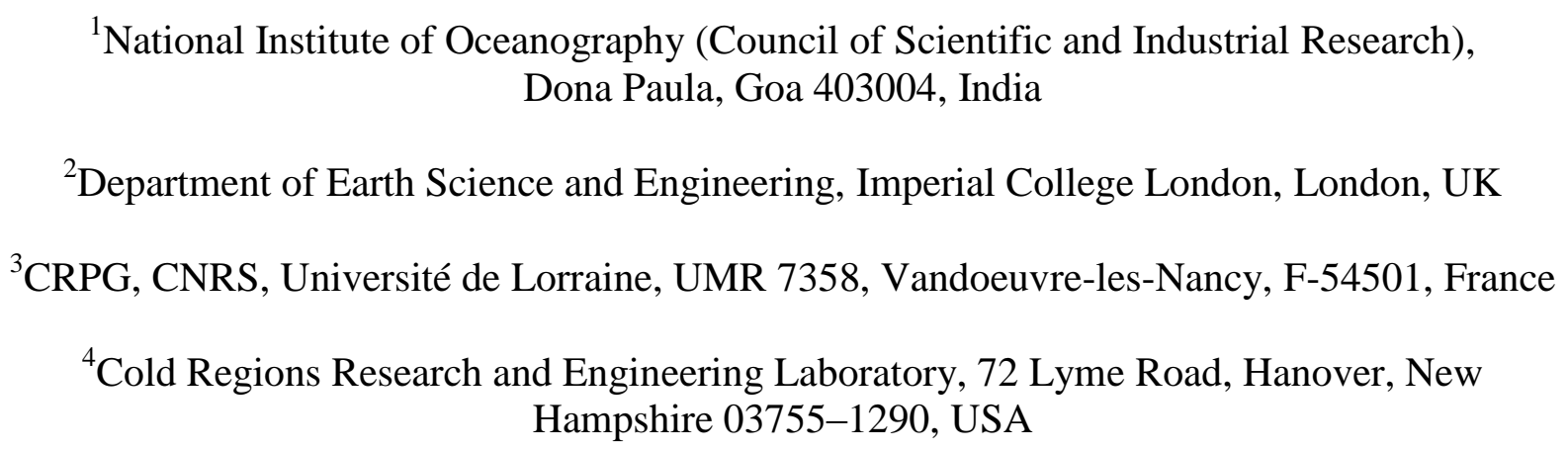


Key Points:

- The ranges of different types of cosmic spherules suggest increasing mass fractionation consistent with estimates of peak temperature from textures.

- Porphyritic and barred spherules have derivation of a significant proportion mainly from ordinary and carbonaceous chondrites, respectively.

- G-types have experienced little mass fractionation with oxygen isotope composition similar to carbonaceous chondrite precursors.

37

38

39

40 


\section{Abstract:}

42 Cosmic spherules are micrometeorites that melt at high altitude as they enter Earth's atmosphere and their oxygen isotope compositions are partially or completely inherited from the upper atmosphere, depending on the heating experienced and the nature of their precursor materials. In this study, the three oxygen isotope compositions of 137 cosmic spherules are determined using 277 in-situ analyses by ion probe. Particles of each different type of cosmic spherule (scoriaceous, porphyritic, cryptocrystalline, barred, glass, calcium aluminium and titanium (CAT), G-type and I-type) in the diameter range $\sim 52-480 \mu \mathrm{m}$ were analysed. The results confirm that the three oxygen isotope compositions of melted micrometeorites reflect a combination of their precursor composition, exchange with the atmosphere and mass fractionation owing to evaporation during entry heating. The data appear to reveal an increase in average $\delta^{18} \mathrm{O}$ values of silicate dominated (S-type) spherules in the series scoriaceous $<$ porphyritic $<$ barred $<$ glass $<$ CAT spherules $(\sim 20,22,25,26$ and $50 \%)$ that is consistent with the evolution of oxygen isotopes by mass fractionation owing to increased average entry heating. The trend of $\delta^{17,18} \mathrm{O}$ is broadly parallel to the terrestrial fractionation line and thus suggests mass fractionation dominates changes in isotopic composition, with atmospheric exchange a less significant effect. The $\Delta^{17} \mathrm{O}$ values of spherules, therefore, are mostly preserved and suggest that $\sim 80 \%$ of particles are related to the carbonaceous chondrites (CC) and are probably samples of C-type asteroids. The genetic relationships between different S-types can also be determined with scoriaceous, barred and cryptocrystalline spherules mostly having low $\Delta^{17} \mathrm{O}$ values $(\leq \mathbf{0} \%$ o) suggesting they are mainly

62 derived from CC-like sources, whilst porphyritic mostly have positive $\Delta^{17} \mathrm{O}$ (>0\%) suggesting they are largely from ordinary chondrite (OC)-like sources related to S(IV)-type asteroids. Glassy and CAT-spherules have $\Delta^{17} \mathrm{O}$ values suggesting they formed by intense 
entry heating of both $\mathrm{CC}$ and $\mathrm{OC}$-like materials. I-type cosmic spherules have a narrow range of $\delta^{17} \mathrm{O}(\sim 20-25 \%)$ and $\delta^{18} \mathrm{O}(\sim 38-48 \%)$ values, with $\Delta^{17} \mathrm{O}(\sim 0 \%)$ indicating their oxygen is obtained entirely from the Earth's atmosphere, albeit with significant mass fractionation owing to evaporation during entry heating. The observed range of $\delta^{18} \mathrm{O}$ with size is suggested here to reflect entry angle with high values representing enhanced heating at high angle. Finally, G-type cosmic spherules have unexpected isotopic compositions suggesting little mass-fractionation from a CC-like source and are suggested to have sulphide-silicate precursors with relatively low melting temperatures. The results of this study provide vital assessment of the wider population of extraterrestrial dust arriving to the Earth.

\section{Plain Language Summary}

Extraterrestrial dust particles are often intensely heated during atmospheric entry, inducing significant changes of their mineralogy and chemical and isotopic compositions. Such heating processes make difficult to identify the nature of their precursors, and thus the sources of extraterrestrial dust falling on Earth. In this study, we report the oxygen isotope compositions of a large collection of cosmic spherules to assess their sources in the solar system. Previous studies have shown that oxygen isotopes are altered by heating and mixing with the atmosphere, but have yet analysed relatively small numbers of particles. Our results suggest that $80 \%$ of particles are related to carbonaceous chondrites, and are thus samples of C-type asteroids, with most of the remainder being related to ordinary chondrites that sample S-type asteroids. We also show, for the first time, that G-type cosmic spherules have a C-type asteroid source. We conclude that oxygen isotopes provide a valuable probe of the sources of extraterrestrial dust despite the changes that occur during atmospheric heating. 


\section{INTRODUCTION}

1

Micrometeorites are the most abundant extraterrestrial materials reaching the Earth's surface on an annual basis (Love and Brownlee, 1993). Cosmic spherules are extraterrestrial particles that undergo significant melting during atmospheric entry and represent micrometeorites that have experienced high temperature during passage through the atmosphere. Although a large fraction of this material never makes it to Earth's surface and is evaporates (e.g. Love and Brownlee, 1991), surviving particles still represent the most significant contributors of extraterrestrial material to the Earth's surface (Taylor et al., 1998; Yada et al., 2004; Plane, 2012; Prasad et al., 2013). Micrometeorites provide information on the nature of their Extraterrestrial parent bodies, the processes operating during atmospheric entry and the composition of the Earth's atmosphere. Extraterrestrial material that enters the upper atmosphere at $>100 \mathrm{~km}$ altitude experiences gas drag heating thereby changing their original chemical and isotopic properties (Kurat et al. 1994; Beckerling and Bischoff 1995; Brownlee et al. 1997; Greshake et al. 1998; Engrand et al., 2005; Genge et al., 2008; Cordier et al., 2011; Rudraswami et al., 2012, 2015, 2016). The oxygen isotope compositions of particles that survive atmospheric entry are thus related to those of both their precursors and the upper atmosphere. Currently, the oxygen isotope composition of the upper atmosphere (i.e. > $60 \mathrm{~km}$ ) has not been determined yet and any isotopic information above this altitude need to be deciphered from micrometeorites as most of these particles have undergone heating leading to isotopic exchange between $\sim 80$ and 120 km (Thiemens et al., 1995; Pack et al., 2017).

The present study undertakes oxygen isotope analyses of different types of micrometeorites in large numbers from partially heated scoriaceous micrometeorites to the 
most heated cosmic spherules is an attempt to constrain the contribution of heating, exchange with atmosphere, and precursor to their isotopic composition. The ideal cosmic spherules for deciphering the composition of the upper atmosphere are I (iron) type spherules since all of their oxygen is acquired from the atmosphere (Pack et al., 2017). The analyses of Pack et al., (2017) suggest that it was possible to identify the $\delta^{17,18} \mathrm{O}$ in the upper atmosphere and concluded it is similar to the troposphere. The current study employs a larger set of I-type cosmic spherules to better evaluate their oxygen isotope composition and alteration during atmospheric entry.

\section{Unmelted micrometeorites and interplanetary dust particles have experienced} minimal chemical and isotopic alteration during atmospheric entry, due to high zenith angle and low entry velocity. Hence, they are invaluable witnesses for estimating the pre-atmospheric oxygen isotopic composition of the altered S-type cosmic spherules and scoriaceous micrometeorites. The mineralogy and bulk chemical compositions of cosmic Spherules are changed significantly, but previous studies suggest that the $\Delta^{17} \mathrm{O}$ abundance is largely preserved in some significantly altered cosmic spherules (Engrand et al., 2005; Yada et al., 2005; Suavet et al., 2010; Cordier and Folco, 2014; Rudraswami et al., 2015, 2016; Goderis et al., 2019). Here we report the in-situ analyses of 277 spots for oxygen isotopes from selected 137 cosmic spherules of different types (S, I and G-type) using an ion microprobe to outline the variation during atmospheric entry.

\section{SAMPLE COLLECTION}

The cosmic spherules are collected from the central Indian Ocean from the depth of $\sim 5200 \mathrm{~m}$ using a grab sampler having size $50 \times 50 \mathrm{~cm}$ (length $\times$ breadth). This grab can 
penetrate to a depth of $\sim 15 \mathrm{~cm}$ and pick up $\sim 45 \mathrm{~kg}$ of wet sediments. The details of the sampling methodology have been reported in previous research publications, namely, Rudraswami et al., 2011, 2012; Prasad et al., 2013. Antarctica samples were collected from South Pole Water Well (SPWW), Amundsen-Scott South Pole Station, below 100 m from the snow surface. The well dimension are $\sim 24 \mathrm{~m}$ in diameter with water depth of $\sim 15 \mathrm{~m}$ with a capacity of $\sim 5000 \mathrm{~m}^{3}$ (Taylor et al., 1998, 2000). In addition, further Antarctica samples were collected near Indian research station Maitri by melting blue ice and sieving using 50 $\mu \mathrm{m}$ mesh. Nearly $\sim 50$ tons of blue ice was melted to extract the trapped cosmic dust particles that are expected to exhibit minimal terrestrial alteration (Rudraswami et al. 2018). The selection of 137 particles were made after investigating $\sim 3000, \sim 1500, \sim 2000$ cosmic spherules from deep-sea, SPWW, Maitri collection, respectively. The collected samples were mounted on epoxy resin for polishing to be able to use for further electron microscopy and isotopic studies using ion microprobe. Silicate (S) type particles analysed are as follows: scoriaceous (13), porphyritic (11), barred (18), cryptocrystalline (22), glass (37). A further Itype (15), G-type (19) and CAT (Calcium-Aluminium-Titanium, 3) spherules were also measured (Table 1 and Appendix A). Twenty-three spherules with metal bead are reported in Table 2 and Appendix A.

\section{INSTRUMENTAL TECHNIQUES} chemical composition and type of spherules was performed on polished sections. The scanning electron microscope (SEM, JEOL JSM-IT300LV at National Institute of electron probe micro analyzer (EPMA, Cameca SX5 at National Institute of Oceanography, 
165 Goa) was used to acquire the major and minor elemental composition. Most cosmic spherules are in the size range of less than a few hundred $\mu \mathrm{m}$ thus the instrument can perform a detailed study of specific areas in particles. Chemical analyses were performed using electron microprobe on selected cosmic spherules phases with accelerating voltage $\sim 15 \mathrm{kV}, \sim$ beam current $\sim 12 \mathrm{nA}, \sim 1-2 \mu \mathrm{m}$ beam diameter for spot analyses, and $\sim 5 \mu \mathrm{m}$ beam diameter for bulk analyses (Rudraswami et al., 2019). Multiple measurements obtained using different standards are $<1 \%$ error for major elements and for minor elements are within a few percent. oxygen isotope analyses on selected phases or areas. The selected phases were analyzed by $\mathrm{Cs}^{+}$beam having primary current of $\sim 1 \mathrm{nA}$ and beam spot of $\sim 5 \mu \mathrm{m}$. Faraday cups were (Rudraswami et al., 2019). 
We have classified 137 cosmic spherules and partially melted scoriaceous

micrometeorites based on classification scheme by Genge et al. (2008) in order to understand the nature of oxygen isotope composition. The oxygen isotope study of cosmic spherules includes: scoriaceous: 13 particles, porphyritic: 11, barred: 18, cryptocrystalline: 22, glass: 37 and CAT: 3, along with I-type: 15 and G-type: 18 (Table 1 and 2). The back-scattered electron images of nine $S$-type spherules are shown in Fig. 1, while the bulk chemical compositions of all the spherules are summarized in Appendix A. Some of the spherules analysed have FeNi metal bead - these include one porphyritic, three barred, two cryptocrystalline, fourteen glass and one G-type (Fig. 2). Four spherules that have metal beads separated from the main silicate body have a narrow range of oxygen isotope compositions, except MS-I3-P55 (Table 2). The chemical compositions of FeNi beads present in various types of spherules (Fig. 2) are given in Appendix A. The bulk chemical compositions, however, does not show any correlation with oxygen isotope data. Finally, CAT spherules are formed by extreme heating and evaporation during atmospheric entry (Taylor et al., 2000, 2005) and thus provide an endmember of atmospheric entry behaviour.

7

The oxygen isotope compositions of the analysed cosmic spherules are shown by spherule type in Figure 3 and 4 . The over-all compositional range is $\delta^{17} \mathrm{O}-6$ to $+36 \%$ and $\delta^{18} \mathrm{O}-3$ to $+72 \%$ and forms a field scattered mostly around the terrestrial fractionation line (TFL) with some adjacent to carbonaceous chondrite anhydrous mineral (CCAM) line. The S-type spherules show average $\delta^{18} \mathrm{O}$ values that increase in the series porphyritic $<$ barred $<$ cryptocrystalline < glass with values of $\sim 20,22,25$ and $26 \%$, respectively. The $\delta^{18} \mathrm{O}$ range is similar for all groups; however, porphyritic spherules exhibit the smallest range and lowest 
215 values at $\sim 0.7 \%$. The highest $\delta^{18} \mathrm{O}$ values are exhibited by the CAT spherules with an average of $\sim 50 \%$, maximum of $\sim 72 \%$ and a minimum of $\sim 30 \%$. Scoriaceous micrometeorites have the lowest average, maximum and minimum values at $\sim 11,20$ and $3 \%$, respectively.

The $\Delta^{17} \mathrm{O}$ compositions of S-type particles show significant variations (Figure 5).

Porphyritic spherules have a higher average and smaller range at -3 and $2 \%$ compared with barred (-6 and 2\%o) and cryptocrystalline spherules (-5 and 2\%o), the majority of barred and cryptocrystalline spherules plot below the TFL in the three isotope plot, whilst the porphyritic spherules scattered closely around this line, with 7 out of 11 plotting above. For barred and cryptocrystalline spherules the highest $\Delta^{17} \mathrm{O}$ values are those particles with the highest $\delta^{18} \mathrm{O}$ and plot above the TFL. Glass spherules have a broadly similar average to barred, porphyritic and cryptocrystalline combined, and a slightly smaller range at -4 and $3 \%$. Scoriaceous micrometeorites have an average $\Delta^{17} \mathrm{O}$ most similar to barred and cryptocrystalline spherules, but a smaller range at -5 to $0.2 \%$. The smallest range of $\Delta^{17} \mathrm{O}$ amongst silicate dominated particles is exhibited by the CAT spherules and these all plot close to the TFL. and scoriaceous micrometeorites having a small range of high $\delta^{18} \mathrm{O}$ values of $\sim 39$ to $48 \%$. The $\Delta^{17} \mathrm{O}$ ratios of I-types are very low and they all fall within $\sim 1 \%$ of the TFL. None of the Itype spheres measured for oxygen isotopic composition contained metal beads that could be seen in the polished section. However, spherule AAS-62-61-P87 has a void space indicating that bead has been plucked off from the spherules probably during polishing leaving behind void space (Fig. 2). This particle has a thinner magnetite rim $(\sim 3 \mu \mathrm{m})$ than others. The trend of the magnetite thickness versus $\delta^{18} \mathrm{O}$ from the present study, along with that observed by 
240 Engrand et al. (2005), suggests an increase in $\delta^{18} \mathrm{O}$ with thickness (width) of the rim; however, there is no such strong correlation observed with diameter of the I-type spherules (Fig. 6).

In contrast to I-type spherules, G-types have lower $\delta^{18} \mathrm{O}$ values with a range from $\sim 7$ to $35 \%$, with maximum values smaller than any spherule of I-type. The average $\Delta^{17} \mathrm{O}$ of Gtypes ranges between -6 and $1 \%$ and thus plots mainly below the TFL in a three isotope plot (Fig. 5). The $\Delta^{17} \mathrm{O}$ values of G-types increase towards the TFL with increasing $\delta^{18} \mathrm{O}$. There is only one G-type spherule SP005-P207 that has FeNi bead in it (Fig. 2).

The porphyritic spherule SP005-P1078 has two beads with a significant abundance of sulfur $(\sim 17 \mathrm{wt} \%)$. Sulfur at $\sim 5 \mathrm{wt} \%$ was also seen in cryptocrystalline spherules SP005P1176. Few glass spherules have metal beads with sulfur (Appendix A): SP005-P157 ( 33 wt\%), SP005-P1071 ( 15 wt\%), SP005-P34 ( 6 w\%), SP005-P294 (4 wt\%) and SP005-P296 $(\sim 1 \mathrm{wt} \%)$. We have also compiled the data of all metal bead spherules (one porphyritic, three barred, two cryptocrystalline, fourteen glass and one G-type) to explore the trend of $\mathrm{Ni}$ (wt\%) with $\delta^{18} \mathrm{O}$ values with different texture (Fig. 7). Two data sets were examined from different cosmic spherules, one from cryptocrystalline SP005-P1176 and one from glass MS-I35-P39, most of them have nickel composition $<30 \mathrm{wt} \%$ and there is no visible trend of Ni vs. $\delta^{18} \mathrm{O}$. Similarly, we investigated whether $\delta^{18} \mathrm{O}$ varies with size of cosmic spherules (Fig. 8) with the expectation that heating, and thus mass fractionation, may increase with particle size. No correlation, however, was observed with the size of particles.

262 Finally the $\delta^{18} \mathrm{O}$ and $\Delta^{17} \mathrm{O}$ data was compared with those of meteorites as shown in Figure 9 since previous studies have suggested that the oxygen isotope compositions of spherules can be related to those of their precursors by consideration of the nature of exchange 
processes occurring during entry heating Suavet et al. (2010).

266

267

\section{DISCUSSION}

268

\subsection{Oxygen isotope of I-type cosmic spherules}

270

I-type cosmic spherules are thought to form by the atmospheric entry of FeNi metal interplanetary dust particles rather than by separation from silicate particles. Their origin as metal grains is supported by their sizes, which are larger than immiscible metal beads present in S-type cosmic spherules. Furthermore, the flux of micrometeorites is significantly larger than that of meteorites, implying that I-types are not separated from these larger meteoroids (e.g. Genge et al., 2017). The presence of the spallogenic isotope

${ }^{10} \mathrm{Be}$ within I-type spherules confirms they were exposed in space as metal grains, since this highly lithophile element would have been removed if they separated from silicates (Yiou et al., 1985). The textures and mineralogies of I-type cosmic spherules are also consistent with their formation by progressive oxidation with the formation of an oxide mantle at the expense of the FeNi metal bead (Brownlee et al., 1984; Engrand et al., 2005; Genge et al., 2017b). Itype cosmic spherules, therefore, could be used as a proxy for the isotopic composition of the thermosphere/mesosphere and stratosphere. Since this requires an independent assessment of the degree of evaporation, and thus analyses of $\delta^{56} \mathrm{Fe}$ (Engrand et al. 2005; Pack et al., 2017) it was not possible in the current study.

Although most are formed by melting of metal grains, there are probably some Itype particles formed by metal separation from S-types, as suggested by Brownlee et al. (1984), since metal-beads are observed to migrate to the margins of these spherules during 
deceleration (Genge and Grady, 1998). These are likely to be in the minority, and likely to be of smaller size $(<50 \mu \mathrm{m}$ in diameter). In such cases, there is bound to be some iron isotope fractionation during immiscibility that could potentially influence the use of $\delta^{56} \mathrm{Fe}$ as a proxy for evaporation. Fractionation is, however, likely minor during immiscibility in comparison to evaporation simply because the mass difference is small and diffusion rates in silicate melts are more controlled by electronic structure and speciation rather than atomic mass. In the present study, we consider all I-type particles to have had FeNi metal precursors.

The oxygen isotope of 15 I-types has $\delta^{18} \mathrm{O}$ ranging between $38.5-48.4 \%$, while for $\delta^{17} \mathrm{O}$ of $20.0-25.2 \%$ with $\Delta^{17} \mathrm{O}$ value within analytical uncertainty of the terrestrial fractionation value. The spread in $\delta^{18} \mathrm{O}$ is $\sim 10 \%$, while that in $\delta^{17} \mathrm{O}$ are $\sim 5 \%$. These isotopic values cover a larger range and are heavier than those used by Pack et al., (2017) as a proxy for mesospheric composition $\left(\delta^{17} \mathrm{O}=19.3-21.6 \%\right.$, $\left.\delta^{18} \mathrm{O}=37.8-42.5 \%\right)$; albeit on only four cosmic spherules between $\sim 400$ and $550 \mu \mathrm{m}$ in size. In contrast Engrand et al (2005) obtained a wider range of values of $\left(\delta^{17} \mathrm{O}=19.1\right.$ to $29.4 \%$, $\delta^{18} \mathrm{O}=38.4$ to $57.4 \%$ o $)$ for a set of twelve I-type spherules ranging in size from $\sim 408$ to $575 \mu \mathrm{m}$. They showed an increase in $\delta^{18} \mathrm{O}$ with the diameter of the spherule which is also true for the thickness of the magnetite rim (Fig. 6). The thickness of rim correlation seen in many I-type spherules also holds true for the current study where rim thickness is much smaller $(<11 \mu \mathrm{m})$. As the oxidised rim thickness increases so does the $\delta^{18} \mathrm{O}$ value, however, this correlation also holds over the entire diameter range of the spherules.

Engrand et al. (2005) indicated that $\delta^{18} \mathrm{O}$ correlates with size for particles larger than $>400 \mu \mathrm{m}$. I-type particles from the present study are less than $300 \mu \mathrm{m}$ and have a smaller 
315 range and average of $\delta^{18} \mathrm{O}$ than the larger spherules studied by Engrand et al., (2005), but have a similar minimum $\delta^{18} \mathrm{O}$. An increasing trend of $\delta^{18} \mathrm{O}$ with size was observed except for few outlier datasets such as AAS-38-167-1-P115 and AAS-38-167-1-P116 (circled in Fig. 6). The oxygen isotope data values did not correlate with the total abundance of magnetite in I-type spherules, which is likely to be a proxy for total oxidation, nevertheless, $\delta^{18} \mathrm{O}$ strongly correlated with the thickness of the magnetite rim (Fig. 6 and Table 2). The thickness of the rim is large in spherules dominated by magnetite unlike those that are wustite-dominated. This undoubtedly relates to increased mass fractionation as a result of larger degrees of evaporation from larger particles - largely a consequence of their higher peak temperatures (Genge, 2016). The increase in the range and maximum value of $\delta^{18} \mathrm{O}$ with particle size is consistent with the variation of their peak temperatures with entry parameters as modelled numerically by Genge (2016). At near vertical entry angle peak temperature increases rapidly with particle size, resulting in significant increases in mass fractionation, whilst at low entry angles peak temperature increases less with size, causing smaller changes constraints on the entry heating of these particles.

I-types with metal beads and smaller magnetite rims have been shown to have lower $\delta^{18} \mathrm{O}$ due to lower degrees of heating than those with no bead and thick magnetite rim (Engrand et al., 2005); however, we cannot verify this as no metal bead-bearing I-types were analysed in the current study. Furthermore, without $\delta^{56} \mathrm{Fe}$ measurements we cannot independently determine the degree of evaporation, and thus the magnitude of mass fractionation in oxygen cannot be determined, except by Rayleigh fractionation with an assumed atmospheric composition. The range of mass fractionation in I-type spherules is nevertheless consistent with previous studies. These spherules have experienced a similar 
range of evaporation, albeit greater than the spherules observed by Pack et al (2017) and less than some of those analysed by Engrand et al. (2005).

At altitudes $>100 \mathrm{~km}$ in the thermosphere, increases in $\delta^{17,18} \mathrm{O}$ of spherules could be caused by dissociation and recombination rates of oxygen molecule resulting in enrichment of heavier isotopes by mass independent fractionation (Colegrove et al. 1965; Thiemens et al., 1995). The I-type spherules in this study have oxygen isotope compositions within uncertainty of the TFL; hence the average atmospheric oxygen have acquired $\Delta^{17} \mathrm{O}=0.3 \%$ within the uncertainty of $\sim 0.6 \%$ ( 2 standard deviation). We can, therefore, safely say that if the thermosphere has a $\Delta^{17} \mathrm{O}$ value greater than $1 \%$ of the troposphere, then only a small proportion of this oxygen is incorporated into I-type spherules and may be further diluted by oxygen acquired at peak deceleration at lower altitudes in the mesosphere. Higher precision oxygen isotope compositions such as reported by Pack et al. (2017) might be capable of resolving $\Delta^{17} \mathrm{O}$ differences arising from capture of thermospheric gas with oxygen isotope compositions that diverge from the TFL. However, these high precision data reported no thermospheric oxygen with higher $\Delta^{17} \mathrm{O}$ involved in the oxidation of the I-type cosmic spherules. We would predict that those spherules with the lowest entry angles are most likely to exhibit such divergences since at any particular size these undergo more of their deceleration at higher altitude. These spherules are likely to exhibit the lowest $\delta^{18} \mathrm{O}$ values for their size since low angle particles have lower peak temperatures and thus experience less evaporation and mass fractionation.

\subsection{Oxygen isotope of S-type cosmic spherules}

The oxygen isotope compositions of S-type cosmic spherules and scoriaceous 
component of their pre-atmospheric precursors. Silicate micrometeorites, therefore, inherit the isotopic composition of their precursor which is then modified during atmospheric entry by exchange with atmospheric oxygen and mass-fractionation owing to partial evaporation on heating. These two processes cause oxygen isotope compositions to evolve in different ways on an oxygen three isotope plot. Mass-fractionation owing to preferential loss of light oxygen during partial evaporation causes changes in composition according to relative mass of the isotope. On a three isotope plot, therefore, oxygen isotope compositions under a massdependent regime evolve parallel to the TFL along a slope 0.52 line towards $\delta^{18} \mathrm{O}$-rich values (Figs. 3 and 4). In contrast exchange with air causes isotope compositions to converge towards the oxygen isotope composition of the atmosphere resulting in $\Delta^{17} \mathrm{O}$ values approaching zero whilst the $\delta^{18} \mathrm{O}$ value trends towards that of the air. These two processes have been previously discussed by Sauvet et al. (2010), Cordier et al (2011) and Van Ginneken et al. (2017) and are superimposed on the isotopic variability of the original precursors. (Fig. 9).

Two broad genetic groups of S-type cosmic spherule can be recognised by their $\Delta^{17} \mathrm{O}$ values within the analysed particles. Porphyritic spherules have higher average $\Delta^{17} \mathrm{O}$ values scattered at small values $\left(\Delta^{17} \mathrm{O}=\sim \pm 2 \%\right.$ o $)$ above and similarly for below the TFL, whilst barred and cryptocrystalline spherules have lower average $\Delta^{17} \mathrm{O}$ values that fall mainly below the TFL. Porphyritic spherules have $\Delta^{17} \mathrm{O}$ similar to Ordinary, Enstatite, $\mathrm{R}$ and $\mathrm{CI}$ chondrites, whilst barred and cryptocrystalline spherules have lower values consistent with $\mathrm{CM}, \mathrm{CR}, \mathrm{CV}$ and $\mathrm{CO}$ chondrites (Fig. 9). Although broadly consistent with these meteorite groups, the isotope compositions of porphyritic, barred and cryptocrystalline spherules significantly overlap. The small number of barred and cryptocrystalline spherules $(\sim 10 \%)$ with the highest 
$389 \Delta \Delta^{17} \mathrm{O}$ values, however, are consistent with evolution from CI and ordinary chondrite-like materials, whilst those porphyritic spherules with $\Delta^{17} \mathrm{O}<-0.5 \%$ is consistent with $\mathrm{CM}, \mathrm{CR}$ and perhaps $\mathbf{C V}$, CK sources, particularly if their $\Delta^{17} \mathrm{O}$ has evolved towards zero as a result of exchange with air. Eighteen percent of spherules from porphyritic, barred, cryptocrystalline, glass, scoriaceous micrometeorites have $\Delta^{17} \mathrm{O}>-0.5 \%$ and $\delta^{18} \mathrm{O}$ less than CI chondrite and can only be derived from precursors with oxygen isotopes similar to Ordinary or Enstatite chondrites as previously suggested by Cordier et al. (2011). Glassy spherules analysed in this study have a broader range of $\Delta^{17} \mathrm{O}$ than barred, cryptocrystalline and porphyritic spherules, which nearly matches the range of all three groups suggesting these particles can be derived from any of the chondrite groups. grained materials such as chondrite matrix.

410

Van Ginneken et al (2017) found one cryptocrystalline spherule $\Delta^{17} \mathrm{O}<-2 \%$ (Group 2 of Van Ginneken et al., (2017)), whilst 6 particles had $\Delta^{17} \mathrm{O}>-0.5 \%$ (Group 3 and 4). The 
current study reveals that the oxygen isotopes of cryptocrystalline spherules cover a wide range rather than previous observed with the majority $(\sim 70 \%)$ having $\Delta^{17} \mathrm{O}<-0.5 \%$. These are thus similar to barred olivine spherules and derived from $\mathrm{CR}, \mathrm{CM}, \mathrm{CO}$ or $\mathrm{CV}$ chondrites (Fig. 5 and 9). This implies that cryptocrystalline spherules are formed by increased heating of precursors similar to those of barred olivine spherules, a suggestion consistent with the higher average $\delta^{18} \mathrm{O}$ of cryptocrystalline particles observed in the current study. Likewise, the broad range of $\Delta^{17} \mathrm{O}$ in glassy spherules and their higher average $\delta^{18} \mathrm{O}$ is consistent with their formation by increased heating of precursors similar to both porphyritic olivine and cryptocrystalline spherules.

The increase in $\delta^{18} \mathrm{O}$ in S-type cosmic spherules, relative to their precursors, resulting from entry heating of S-type cannot be directly related to the degree of heating and evaporation without knowledge of the degree of atmospheric mixing and the composition of the precursor., Alexander et al. (2002), however, have shown that cosmic spherules that suffered the highest peak temperatures also exhibit the largest increase in $\delta^{18} \mathrm{O}$ values, implying that evaporation dominates $\delta^{18} \mathrm{O}$ evolution. Exchange with air makes it more challenging to assess $\delta^{18} \mathrm{O}$ in terms of heating since it will also cause increases in $\delta^{18} \mathrm{O}$ for particles with values less than that of air $\left(\delta^{18} \mathrm{O}=23.5 \%\right.$; Thiemens et al., 1995). Exchange with air means the $\delta^{18} \mathrm{O}$ cannot be directly related to heating alone. Whether $\delta^{18} \mathrm{O}$ increase is largely the result of exchange of atmospheric oxygen in silicate melt or mass fractionation by evaporation depends on which of these two processes dominate.

The average $\delta^{18} \mathrm{O}$ observed in the current study increases in the series porphyritic< barred $<$ cryptocrystalline $<$ glassy $<$ CAT spherules. The textures of this series of spherules has been interpreted as representing increasing peak temperature, with texture controlled by 
crystallisation under increasing super-cooling due to progressive destruction of crystallisation nuclei with increasing temperature (Taylor et al., 1991; Genge et al. 2008). The increase in average $\delta^{18} \mathrm{O}$ through this series is, therefore, evidence that mass fractionation owing to heating dominates over exchange with the atmosphere. The approximately equal maximum and minimum values of $\Delta^{17} \mathrm{O}$ with $\delta^{18} \mathrm{O}$, shown by the band of data points in a three isotope plot around TFL (Fig. 5), also testifies to the dominance of mass fractionation. If exchange with air was dominant, in contrast, $\Delta^{17} \mathrm{O}$ would become less with increasing $\delta^{18} \mathrm{O}$ values up until those of air.

The extreme heating of the calcium aluminium titanium-rich (CAT) spherules enriched in refractory elements such as $\mathrm{Ca}, \mathrm{Al}$, and $\mathrm{Ti}$ makes their oxygen isotope composition very interesting (Taylor et al., 2000; Genge et al., 2008). The oxygen isotope composition of $\delta^{17,18} \mathrm{O}$ is much heavier in these particles than any other spherules indicating not only atmospheric exchange but also coupled evaporation during entry. CAT spherules with the highest average $\delta^{18} \mathrm{O}$ values of the analysed particles are consistent with the extreme partial evaporation implied by their refractory compositions (Taylor et al., 2000).

Previous bulk oxygen isotope measurements of high $\mathrm{Ca}$ and $\mathrm{Al}$ spherules made by Cordier et al. (2011) have shown significantly lower $\delta^{18} \mathrm{O}$ values than observed here, having a range of $\sim 15$ to $19 \%$, with only one having a value of $\sim 28 \%$. It is possible the spherules analysed by Cordier et al., (2011) are fragments of Ca-Al-rich precursors, rather than the refractory products of extreme evaporation. One CAT spherule (MY240184) analysed by Yada et al. (2005) yielded a high $\delta^{18} \mathrm{O}$ value of $\sim 93 \%$. This value is much higher than our highest $\delta^{18} \mathrm{O}$ value of $\sim 71 \%$, and our lowest value is also higher than given by Cordier et al. (2011). The extremely high value of $\delta^{18} \mathrm{O}$ indicates excessive heating and evaporation for an 
extended period during atmospheric entry, which results in evaporative loss of moderately volatile elements, such as $\mathrm{Fe}$, followed by $\mathrm{Si}$ and $\mathrm{Mg}$, and a corresponding enrichment of the remaining $\mathrm{Ca}, \mathrm{Al}$ and $\mathrm{Ti}$ (Wang et al., 2001, Yada et al., 2005). That one of the CAT spherules (SP007-P236) has the highest $\delta^{18} \mathrm{O}$ value $(\sim 71 \%$ ) of any of the S-type spherules in our study supports the above assertion.

All CAT spherules have small $\Delta^{17} \mathrm{O}$ values close to the TFL largely similar to porphyritic spherules, suggesting their precursors might be derived from a similar source (Fig. 5). That all the CAT spherules are derived from the same source is surprising since extreme partial evaporation might be expected to largely source independent, if most likely for those sources with higher average entry velocities, and thus eccentricities. Nevertheless, Cordier and Folco (2014) analyzed several CAT spherules with most of them have oxygen isotopic composition below TFL line, although as suggested above these may have been derived from refractory precursors and thus different to typical CAT spherules. The lack of isotopic diversity in CAT spherules observed in this study could, however, be due to the low number of particles and poor sampling statistics compared to other types of cosmic spherules (Fig. 9). At present, it seems that there are few CAT spherules above and some below TFL, indicating two different populations that do not overlap each other. Based on the above/below TFL dichotomy it is likely that CAT spherules can originate from both $\mathrm{CC}$ and $\mathrm{OC}$ bodies, and can be formed either by extreme evaporation of chondritic precursors, or by melting of refractory precursors, presumably including fragments of CAIs.

The present study of scoriaceous, porphyritic, barred, cryptocrystalline, glass, and 
$60-300 \mu \mathrm{m})$ have sources dominated $(\sim 80 \%)$ by carbonaceous chondrites, with the remainder

489

490

491

492

493

494

495

496

497

498

499

500

501

502

503

504

505

506

507

508

509

510

511

derived from sources similar to ordinary chondrites. Experimental oxygen isotope analyses of different type of S-type cosmic spherules has demonstrated an increase in $\delta^{17,18} \mathrm{O}$ due to alteration during atmospheric entry (Fig. 3). The alteration in barred, cryptocrystalline, glass spherules are similar as they fall on TF line. Some of the porphyritic spherules seem to be preserved $\delta^{17,18} \mathrm{O}$ and does seem to alter significantly like glass, barred, cryptocrystalline spherules. This is also observed in previous studies that have shown some data on CCAM line (Rudraswami et al., 2015, 2016). Among the S-type cosmic spherules, the scoriaceous spherules appear to have been the least affected by atmospheric entry since their oxygen isotope fall mainly on CCAM line (Fig. 4). The bulk of the data from scoriaceous and porphyritic have $\Delta^{17} \mathrm{O}<0 \%$ similar to those seen in carbonaceous chondrites (Fig. 5), although with significant numbers of porphyritic spherules having higher values. Similarly barred, cryptocrystalline, and G-type mostly have lower $\Delta^{17} \mathrm{O}$ than the TFL and are likewise related to carbonaceous chondrite. By comparison glassy spherules have a range of compositions. The data suggest that $\Delta^{17} \mathrm{O}$ does not alter much irrespective of altitude, but variation in $\delta^{17,18} \mathrm{O}$ is visible. Although the $\Delta^{17} \mathrm{O}$ tends to increase with increase in $\delta^{17,18} \mathrm{O}$ values (Rudraswami et al., 2016), most of the partially altered scoriaceous particles show $\Delta{ }^{17} \mathrm{O}<0 \%$, suggesting a carbonaceous chondrite origin as seen in Figs. 4 and 5, rather than as a consequence of heating. The origin of these particles from precursors consisting of hydrated fine-grained matrix is supported by their textures and mineralogy (Genge et al., 2008; Taylor et al., 2012; Badyukov et al., 2018; Suttle et al., 2019) and the presence of relict cores of matrix (Genge, 2006) and fragmented olivine within some particles (Genge et al., 2017a). 
Finally, no significant difference was noted between the isotopic compositions of S-

513

type spherules with and without metal-beads. The lack of discrete compositions for spherules with FeNi metal beads suggests that these can be present within spherules derived from any chondritic source, in contrast to the suggestion of Cordier et al., (2011b) based on the Nicontents of olivines that argued metal separation is most common for those particles derived from carbonaceous chondrite-like sources. The relatively small number of these particles analysed, however, may not sufficiently reveal whether metal beads are more common from one source or another. The separation of metal owing to deceleration during flight, or the lack of exposure of metal beads on the plane of section, are likely to make this comparison less than rigorous.

Some the particles that have metal beads need to be looked for source related variation, such as, whether they are abundant in CC-derived (below TFL), OC-derived (above TFL), or both. Also, it will be remarkable to see if the metal beads more or less abundant in $\delta^{18} \mathrm{O}$-rich particles that have experienced more intense heating and probably higher decelerations. The presence of metal beads is related to low $\delta^{18} \mathrm{O}$ in I-type spherule compared to those with magnetite rich I-type particles demonstrating the massdependent fractionation by evaporation for particles during atmospheric entry (Engrand et al., 2005). Metal beads are present in all types of spherules in small number, except scoriaceous micrometeorites, and rarely in porphyritic spherules (Rudraswami et al., 2014). The oxygen isotope data on barred spherules with at least one metal bead has shown low $\delta^{18} \mathrm{O}$ values of $\sim 12-16 \%$, except MS-I3-P21 that has $\sim 23 \%$ probably due to larger size resulting in enrichment of heavier oxygen isotope during entry. This variation in oxygen isotope composition in barred spherules is similar to the I-type spherule correlation as suggested by Engrand et al. (2005). The Ni content in MS-I3-P21 is less $(\sim 19 \mathrm{wt} \%)$ compared to other 
three barred spherules (23-30 wt\%) indicating no relation as far as barred spherules are considered, however, we cannot draw a statistically significant conclusion with few particles (Fig. 7).

Glass spherules have undergone more heating than barred spherules and often have metal beads. The $\delta^{18} \mathrm{O}$ values in metal-bearing glass spherules have shown scatter with the increase in $\mathrm{Ni}$ content in metal bead (Fig. 7). The Fe is more volatile than $\mathrm{Ni}$ and having large presence of $\mathrm{Ni}$ in metal bead, and those spherules showing low $\delta^{18} \mathrm{O}$ is surprising and has to do primarily with precursor properties and entry parameters. However, if the oxygen isotope composition of precursor were similar, then Fe would have got evaporated proportionately showing relation to $\delta^{18} \mathrm{O}$. MS-I35-P39 is the only glass spherule where it has shown high Ni content of $\sim 64 \mathrm{wt} \%$; one of the reasons is a different type of precursors that is contributed and also the entry parameter as indicated earlier. (Fig. 7). We have measured a single G-type spherule with bead that has very low nickel content $(\sim 10 \mathrm{wt} \%)$ and $\delta^{18} \mathrm{O}$ value of $\sim 28 \%$ which fit in range of bead bearing glass spherules. The metal bead in porphyritic spherule is strange, and SP005-P1078 has two metal bead where its average composition has shown presence of sulfur ( $17 \mathrm{wt} \%)$ along with Fe and Ni (Appendix A) indicating that these metals are not due to entry phenomena but were existing in its precursor, and most likely have got altered due to oxidation during entry (Fig. 2a). The $\delta^{18} \mathrm{O}$ composition of $\sim 32 \%$ is much larger and comparable to other spherules that have shown some sulfur composition in glass spherules (SP005-P157, SP005-P1071, SP005-P34, SP005-P294, and SP005-P296). The lone cryptocrystalline spherule also has low $\delta^{18} \mathrm{O}$ values compared to high Ni content of $\sim 64 \mathrm{wt} \%$. Four particles, namely two from glass, one from CAT and one from I-type, has shown metal bead escaped from the spherules (Fig. 2). The $\delta^{18} \mathrm{O}$ of the spherules that have escaped segregated metal bead is $\sim 35-40 \%$, except MS-I3-P55 with low values. However, 
562 there are exception and the general trend favours increase in $\delta^{18} \mathrm{O}$ values with the high $\mathrm{Ni}$ content (Fig. 7). This is due to heating and melting of the particles that lead to evaporation thereby increasing the $\delta^{18} \mathrm{O}$, and oxidation resulting in increase of $\mathrm{Ni}$ in the residual metal.

No systematic variation of $\delta^{18} \mathrm{O}$ of scoriaceous micrometeorites with size is observed, but for porphyritic spherules there is slight increase in the maximum and minimum $\delta^{18} \mathrm{O}$ with increasing size of particles, albeit with significant scatter (Fig. 8). There is no clear pattern when it comes to G-type particles. Nevertheless, the particle size has a greater role in elemental loss, owing to increased heating, and also changes the isotopic pattern as it enters the Earth's atmosphere (Rudraswami et al., 2015, 2016). It is likely that the lack of welldefined correlations between size and oxygen isotope composition for S-type particles, in contrast to I-types, relates to isotopic variability in the precursors that will partly obscure any systematic variations with entry parameters. Additionally, carbonaceous chondrite precursors are more abundant for smaller size cosmic spherules, with ordinary chondrites contributing more at larger sizes (e.g. Cordier and Folco, 2014). Changes in the sources of cosmic spherules with size complicate evaluating changes in isotopic composition owing to heating since both contribute to final distributions of isotopic composition.

\subsection{Oxygen isotope of G-type Cosmic Spherules}

G-type particles have unique textures largely dominated by magnetite dendrites within 
similar to barred, cryptocrystalline and glass cosmic spherules, and very different from I-

588

589

590

591

592

593

594

595

596

597

598

599

600

601

602

603

604

605

606

607

608

609

610

611

types having low $\delta^{18} \mathrm{O}$ values and a wider range of $\Delta^{17} \mathrm{O}$. The intermediate chemical nature of G-types would imply that their precursors have abundant FeNi metal with sub-ordinate silicate. The low $\delta^{18} \mathrm{O}$ values of most G-types, however, it is not consistent with the significant accretion of atmospheric oxygen and large mass-fractionation as observed for Itypes. Furthermore, the $\delta^{18} \mathrm{O}$ range of G-types is smaller than porphyritic, barred, and cryptocrystalline spherules suggesting less significant mass-fractionation.

The isotopic compositions of G-types are not what would be expected for dense, metal-dominated particles. Some of the observed G-types have compositions close to the CCAM line and thus their precursors are likely to be similar to that observed for porphyritic spherules. Compositions close to the likely precursors suggests minimal mass fractionation and thus partial evaporation of silicates. One possible explanation for the formation of these particles might be if they were mixtures of iron-sulphide and silicates, rather than metal. The low melting temperatures of sulphides may allow spherule formation at a temperature low enough to prevent significant partial evaporation of silicates, precluding significant mass fractionation. Sulphides would react with atmospheric oxygen removing sulphur as $\mathrm{SO}_{2}$ and leaving iron-rich silicate. A similar explanation was proposed earlier for the lack of ironsulphides in I-type cosmic spherules, with vesicles present in metal beads, and extrusion of metal into the surrounding oxide mantle as evidence for oxidative loss of sulphides (Genge et al., 2017). The lack of abundant vesicles in G-types, however, isn't entirely compatible with this interpretation and thus their origins remain enigmatic.

\subsection{Implications}



numbers of spherules is required to enable the interpretation of their sources and the processes affecting them during atmospheric entry. In particular comparisons of the isotope systematics correlated with textural type allows the genetic relationships between different types of particles to be determined. High precision studies of smaller numbers of large particles such as Cordier et al. (2011) and Van Ginneken et al (2017) successfully showed that both mass-fractionation by partial evaporation and exchange with air significantly modify the precursor compositions of cosmic spherules and introduce an inherent uncertainty in the parent body affinity. Cordier et al. (2011) established that those spherules with $\Delta^{17} \mathrm{O}$ values $>-0.5 \%$ and $\delta^{18} \mathrm{O}$ values less than CI chondrites are related to the Ordinary, spherules have sufficiently different $\Delta^{17} \mathrm{O}$ values to necessitate various broad sources. Whilst high precision oxygen isotope studies, provide insights into the relationships between small numbers of large particles, ion microprobe analyses allow comparison of larger populations of particles, including smaller particles down to diameters of $\sim 60 \mu \mathrm{m}$ providing complementary information. In this study, the large number of particles analysed enables the majority of cryptocrystalline particles to be related to the barred olivine spherules through increased heating, whilst glass spherules can be shown to be derived by extensive superheating and nuclei destruction from similar precursors to porphyritic, barred and cryptocrystalline spherules.

The complexity of oxygen isotope evolution during entry heating is a consequence of the simultaneous operation of both mass fractionation and exchange with air. These two processes, however, are likely to be related by the entry parameters of micrometeorites (i.e. entry angle and entry velocity) as suggested by Sauvet et al (2010; 2011). Mass fractionation 
637 by evaporation is mostly dependent on peak temperature and the duration of the heating 638 pulse. Peak temperature increases with entry velocity or with entry angle with high velocity, high entry angle particles experiencing larger peak temperatures and evaporation. The

640 duration of the heating pulse, conversely increases with decreasing entry angle. In two particles experiencing the same peak temperature, for example, the particle with the lower entry angle (which would necessarily have a higher entry velocity to attain the same peak temperature) would experience a larger degree of partial evaporation owing to the longer time spent at high temperature. The time spent above the solidus has been shown to increase from 1-2 s at steep entry angles to $>12 \mathrm{~s}$ at shallow entry angles (e.g. Genge, 2016, 2017). Other properties of particles might, however, influence mass fractionation of oxygen. Volatile- or moderately volatile-rich precursors may undergo more significant partial evaporation than those particles with refractory starting compositions, increasing the mass fractionation of oxygen. The degree of mass-fractionation may, therefore, in part be source dependent, albeit with significant variation related to the different components present, such as fine-grained, volatile-rich matrix, chondrules and calcium-aluminium-inclusions.

2

The exchange of air with cosmic spherules during atmospheric entry may also depend on entry parameters to some extent. At high entry velocity, direct implantation of oxygen into the surface layers of particles is possible since incident energies exceed those of covalent bonding for silicates. At lower velocities the exchange with air is likely to be dominated by chemical reactions, with iron-dominated metal rapidly oxidising by reaction with atmospheric oxygen increasing the degree of exchange. The original oxidation state of the precursor may also be a factor with oxidised materials such as oxide-bearing type II chondrule fragments reacting less with atmospheric oxygen than reduced type I chondrules. Furthermore, reactions that incorporate some of the incident atmospheric oxygen into a gas 
phase may reduce exchange with air by loss of the gas. The reaction of sulphides to produce

$663 \mathrm{SO}_{2}$, for example, is likely to minimize the atmospheric oxygen retained by cosmic 664 spherules and might in part explain the low $\delta^{18} \mathrm{O}$ observed within G-type spherules in this 665 study.

666

The oxygen isotope compositions of I-type cosmic spherules have been determined by several studies (e.g. Engrand et al., 2005; Pack et al., 2017) and have been suggested to be a proxy for mesospheric atmospheric compositions. In these studies, however, the $\Delta^{17} \mathrm{O}$ of particles is usually sufficiently close to TFL to be consistent with an atmospheric composition lacking significant non-mass fractionation effects. An independent means of identifying the degree of evaporation, such as $\delta^{56} \mathrm{Fe}$, is required to use the oxygen isotope compositions as a proxy for those of the atmosphere. Differences in the degree of evaporation suggested by $\delta^{56} \mathrm{Fe}$ and $\delta^{60-64} \mathrm{Ni}$, however, question the validity of this method (e.g. Engrand et al., 2005).

676

Given the expectation that non-mass fractionation effects should become important in the thermosphere, it is expected that spherules that undergo deceleration at the highest altitudes are most likely to show anomalous oxygen that does not fall on the TFL. Particles with the lowest entry angles are most likely to exhibit this behaviour and maybe only a very small proportion of I-types - emphasising the importance of studies of large numbers of particles. Since deceleration altitude is related to particle size, as well as entry velocity, small I-types are most likely to sample thermospheric atmosphere. These particles, which will prove invaluable in probing isotopic composition of the current and past atmosphere of our planet, are currently challenging to analyse at sufficient precision to provide rigorous results. 


\section{CONCLUSIONS}

688

The oxygen isotope compositions of cosmic spherules are a complex signatures of parent body along with atmospheric entry processes arising due to both mass fractionation and isotopic exchange with terrestrial oxygen. We performed 277 in situ oxygen isotope analyses using ion microprobe in 137 micrometeorites collected from deepsea and Antarctica along with many spherules that have metal bead to understand the isotopic pattern. There is an increase in average $\delta^{18} \mathrm{O}$ from scoriaceous $<$ porphyritic $<$ barred $<$ cryptocrystalline $<$ glass $<$ CAT which is clearly related to mass-fractionation and evaporation, and thus peak temperature the particle has acquired during atmospheric entry. It also suggests that mass-fractionation due to heating dominates over exchange with air for S-types. Porphyritic spherules have small $\Delta^{17} \mathrm{O}$ scattered around the TFL, barred and cryptocrystalline spherules fall mainly below the TFL confirming that porphyritic are primarily derived from chondrule fragments, many from OCs, whilst barred and cryptocrystalline are from carbonaceous chondrite matrix. Cryptocrystalline spherules have mostly negative $\Delta^{17} \mathrm{O}$ similar to barred olivine spherules suggesting they form by further melting at higher peak temperature of these particles. It suggests these too are mainly derived from fine-grained carbonaceous chondrite matrix. Glass spherules have $\Delta^{17} \mathrm{O}$ with a range similar (but not quite as large) as porphyritic, barred and cryptocrystalline spherules together. This suggests these form by extensive melting of these types. CAT spherules have small $\Delta^{17} \mathrm{O}$ scattered around TFL and making close associates of porphyritic spherules. G-types that are expected to have significant exchange of atmospheric oxygen and mass-fractionation at high temperatures; however, their small range of $\delta^{18} \mathrm{O}$ suggests the opposite. The G-type with unique dendrites of magnetite and silicate appears to be dominated by carbonaceous chondritic precursors.

711 These show the genetic relationships with precursor materials very well and allow some 
712 quantitative estimates of precursor affinities. The progressive heating of different S-type

713 spherules with bead and non-bead do have some correlation with oxygen isotope enrichment 714 of $\delta^{18} \mathrm{O}$.

715 


\section{ACKNOWLEDGMENT}

717

This research work is supported by GEOSINKS, MOES-PMN, and the PLANEX

718 project. The sample collection from the South Pole water well was funded by National

719 Science Foundation, while from Maitri station and deep-sea sediments collection is funded by

720 MOES-NCAOR and MOES-PMN, respectively. NGR acknowledges the support of CSIR-

721 Raman research fellowship to CRPG-CNRS, Vandoeuvre-les-Nancy, France. We are

722 thankful for the constructive reviews by M. D. Suttle and one anonymous reviewer. This

723 is NIO's contribution No. $\mathrm{xxxx}$.

724

725

APPENDIX A. SUPPLEMENTARY DATA

726 Supplementary data related to this article is provided in the electronic annex.

727 
REFERENCES

729

730

731

732

733

734

735

736

737

738

739

740

741

742

743

744

745

746

747

748

749

750

751

Alexander, C. M. O’D., S. Taylor, J. S. Delaney, P. Ma, and G. F. Herzog (2002), Massdependent fractionation of $\mathrm{Mg}, \mathrm{Si}$, and $\mathrm{Fe}$ isotopes in five stony cosmic spherules, Geochim. Cosmochim. Acta, 66, 173-183.

Badyukov D. D., F. Brandstaetter, and D. Topa (2018), Fine-Grained Scoriaceous and Unmelted Micrometeorites: Sources and Relationships with Cosmic Spherules, Geochemistry International 56, 1071-1083.

Beckerling, W., and A. Bischoff (1995), Occurrence and composition of relict minerals in micrometeorites from Greenland and Antarctica-implications for their origins, Planet. Space Sci., 43, 435-449.

Brownlee, D. E., B. A. Bates, and M. M. Wheelock (1984), Extraterrestrial platinum group nuggets in deep-sea sediments, Nature, 309, 693-695.

Brownlee, D. E., B. Bates, and L. Schram (1997), The elemental composition of stony cosmic spherules, Meteorit. Planet. Sci., 32, 157-175.

Clayton, R. N., N. Onuma, L. Grossman, and T. K. Mayeda (1977), Distribution of pre-solar component in Allende and other carbonaceous chondrites, Earth Planet. Sci. Lett. 34, 209-224.

Clayton, R. N., T. K. Mayeda, E. J. Olsen, and J. N. Goswami (1991), Oxygen isotope studies of ordinary chondrites, Geochim. Cosmochim. Acta, 55, 2317-2337.

Clayton, R. N., and T. K. Mayeda (1999), Oxygen isotope studies of carbonaceous chondrites, Geochim. Cosmochim. Acta, 63, 2089-2104.

Colegrove, F. D., W. B. Hanson, and F. S. Johnson (1965), Eddy diffusion and oxygen transport in the lower therm, J. Geophy. Res., 70, 4931-4941. 
Cordier, C., L. Folco, C. Suavet, C. Sonzogni, and P. Rochette (2011), Major, trace element and oxygen isotope study of glass cosmic spherules of chondritic composition: The record of their source material and atmospheric entry heating, Geochim. Cosmochim. Acta, 75, 5203-5218.

Cordier, C., M. Van Ginneken, and L. Folco (2011a), Nickel abundance in stony cosmic spherules: constraining precursor material and formation mechanisms, Meteorit. Planet. Sci., 46, 1110-1132.

Cordier, C., and L. Folco (2014), Oxygen isotopes in cosmic spherules and the composition of the near Earth interplanetary dust complex, Geochim. Cosmochim. Acta, 146, 18-26.

Engrand, C., K. D. McKeegan, L. A. Leshin, G. F. Herzog, C. Schnabel, L. E. Nyquist, and D. E. Brownlee (2005), Isotopic compositions of oxygen, iron, chromium, and nickel in cosmic spherules: Toward a better comprehension of atmospheric entry heating effects, Geochim. Cosmochim. Acta, 69, 5365-5385.

Genge, M. J., and M. M. Grady (1998), Melted micrometeorites from Antarctic ice with evidence for the separation of immiscible Fe-Ni-S liquids during entry heating, Meteorit. Planet. Sci., 33, 425-434.

Genge, M. J. (2006), Igneous rims on micrometeorites, Geochim. Cosmochim. Acta, 70, 2603-2621.

Genge, M. J., C. Engrand, M. Gounelle, and S. Taylor (2008), The classification of micrometeorites, Meteorit. Planet. Sci., 43, 497-515.

Genge, M. J. (2016), The Origins of I-type Spherules and the Atmospheric Entry of Iron Micrometeoroids, Meteorit. Planet. Sci., 51, 1063-1081.

Genge, M. J. (2017), The entry heating and abundances of basaltic micrometeorites, Meteorit. Planet. Sci., 52, 1000-1013. 
Genge, M. J., M. D. Suttle, and M. Van Ginneken (2017a), Thermal shock fragmentation of $\mathrm{Mg}$ silicates within scoriaceous micrometeorites reveal hydrated asteroidal sources, Geology, 45, 891-894.

Genge, M. J., B. Davies, M. D. Suttle, M. Van Ginneken, and A. G. Tomkins (2017b), The mineralogy and petrology of I-type cosmic spherules: Implications for their sources, origins and identification in sedimentary rocks, Geochim. Cosmochim. Acta, 218, 167-200.

Goderis S., B. Soens, M. S. Huber, S. McKibbin, M. van Ginneken, V. Debaille, R. C. Greenwood, I. Franchi, V. Cnudde, S. V. Malderen, F. Vanhaecke, C. Koeberl, D. Topa, and P. Claeys (2019), Cosmic spherules from Widerøefjellet, Sør Rondane Mountains (East Antarctica) Geochimica et Cosmochimica Acta, 270, 112-143.

Greshake, A., W. Klock, P. Arndt, M. Maetz, G. J. Flynn, S. Bajt, and A. Bischoff (1998), Heating experiments simulating atmospheric entry heating of micrometeorites: Clues to their parent body sources, Meteorit. Planet. Sci., 33, 267-290.

Kurat, G., C. Koeberl, T. Presper, F. Brandstatter, and M. Maurette (1994), Petrology and geochemistry of Antarctic micrometeorites. Geochim. Cosmochim. Acta, 58, 38793904.

Love, S. G., and D. E. Brownlee (1993), A direct measurement of the terrestrial mass accretion rate of cosmic dust, Science, 262, 550-553.

Pack, A., A. Howeling, D. C. Hezel, M. T. Stefanak, A. K. Beck, S. T. M. Peters, S. Sengupta, D. Herwartz, and L. Folco (2017), Tracing the oxygen isotope composition of theupper Earth's atmosphere using cosmic spherules, Nature Communications, 8, 15702 
801

802

803

804

805

806

807

808

809

810

811

812

813

814

815

816

817

818

819

820

821

822

823

824

Plane, J. M. C. (2012), Cosmic dust in the earth's atmosphere. Chem. Soc. Rev., 41, 65076518.

Prasad, M. S., N. G. Rudraswami, and D. K. Panda (2013), Micrometeorite flux on earth during the last $\sim 50,000$ years, J. Geophy. Res., 118, 2381-2399.

Rudraswami, N. G., K. Parashar, and M. S. Prasad (2011), Micrometerand nanometer-sized platinum group nuggets in micrometeorites from deep-sea sediments of the Indian Ocean, Meteorit. Planet. Sci., 46, 470-491.

Rudraswami, N. G., M. S. Prasad, E. V. S. S. K. Babu, T. Vijaya Kumar, W. Feng, and J. M. C. Plane (2012), Fractionation and fragmentation of glass cosmic spherules during atmospheric entry, Geochim. Cosmochim. Acta, 99, 110-127.

Rudraswami, N. G., M. S. Prasad, E. V. S. S. K. Babu, and T. Vijaya Kumar (2014), Chemistry and petrology of Fe-Ni beads from different types of cosmic spherules: implication for precursors. Geochim. Cosmochim. Acta, 145, 139-158.

Rudraswami, N. G., M. S. Prasad, K. Nagashima, and R. H. Jones (2015), Oxygen isotopic composition of relict olivine grains in cosmic spherules: Links to chondrules from carbonaceous chondrites, Geochim. Cosmochim. Acta, 164, 57-70.

Rudraswami, N. G., M. S. Prasad, S. Dey, J. M. C. Plane, W. Feng, J. D. Carrillo-Sánchez, and D. Fernandes (2016), Ablation and Chemical Alteration of Cosmic Dust Particles during Entry into the Earth's Atmosphere, Astrophys. J. Supp. Series, 227, doi:10.3847/0067-0049/227/2/15

Rudraswami, N. G., D. Fernandes, A. K. Naik, M. S. Prasad, J. D. Carrillo-Sánchez, J. M. C. Plane, W. Feng, and S. Taylor (2018), Selective Disparity of Ordinary Chondritic Precursors in Micrometeorite Flux, Astrophys. J., 831, 853:38, doi.: 10.3847/15384357/aaa5f7 
Rudraswami, N. G., Y. Marrocchi, M. S. Prasad, D. Fernandes, J. Villeneuve, and S. Taylor (2019), Oxygen isotopic and chemical composition of chromites in micrometeorites: Evidence of ordinary chondrite precursors, Meteorit. Planet. Sci., 54, 1347-1361.

Suavet, C., A. Alexandre, I. A. Franchi, J. Gattacceca, C. Sonzogni, R. C. Greenwood, L. Folco, and P. Rochette (2010), Identification of the parent bodies of micrometeorites with high-precision oxygen isotope ratios, Earth Planet. Sci. Lett., 293, 313-320.

Suavet, C., C. Cordier, P. Rochette, L. Folco, J. Gattacceca, C. Sonzogni, and D. Damphoffer (2011), Ordinary chondrite-related giant $(>800 \mu \mathrm{m})$ cosmic spherules from the Transantarctic Mountains Antarctica, Geochim. Cosmochim. Acta, 75, 6200-6210.

Suttle, M. D., L. Folco, M. J. Genge, S. S. Russell, J. Najorka, and M. van Ginneken (2019) Intense aqueous alteration on C-type asteroids: Perspectives from giant fine-grained micrometeorites, Geochim. Cosmochim. Acta, 245, 352-373.

Taylor, S., and D. E. Brownlee (1991), Cosmic spherules in the geologic record, Meteoritics, 26, 203-211.

Taylor, S., J. H. Lever, and R. P. Harvey (1998), Accretion rate of cosmic spherules measured at the South Pole, Nature, 392, 899-903.

Taylor, S., J. H. Lever, and R. P. Harvey (2000), Numbers, types, and compositions of an unbiased collection of cosmic spherules, Meteorit. Planet. Sci., 35, 651-666.

Taylor, S., C. M. Alexander, J. Delaney, P. Ma, G. F. Herzog, and C. Engrand (2005), Isotopic fractionation of iron, potassium, and oxygen in stony cosmic spherules: Implications for heating histories and sources, Geochim. Cosmochim. Acta, 69, 26472662.

Taylor, S., G. Matrajt, and Y. Guan (2012), Fine-grained precursors dominate the micrometeorite flux, Meteorit. Planet. Sci., 47, 550-564. 
Thiemens, M. H., T. Jackson, E. C. Zipf, P. W. Erdman, and C. Van Egmond (1995), Carbon dioxide and oxygen isotope anomalies in the mesosphere and stratosphere, Science, 270, 969-972.

Van Ginneken, M., J. Gattacceca, P. Rochette, C. Sonzogni, A. Alexandre, V. Vidal, and M. J. Genge (2017), The parent body controls on cosmic spherule texture: Evidence from the oxygen isotopic compositions of large micrometeorites, Geochim. Cosmochim. Acta, 212, 196-210.

Wang, J., A. M. Davis, R. N. Clayton, T. K. Mayeda, and A. Hashimoto (2001), Chemical and isotopic fractionation during the evaporation of the $\mathrm{FeO}-\mathrm{MgO}-\mathrm{SiO} 2-\mathrm{CaO}-$ A12O3 - TiO2 rare earth element melt system, Geochim. Cosmochim. Acta, 65, 479494.

Yada, T., T. Nakamura, N. Takaoka, T. Noguchi, K. Terada, H. Yano, T. Nakazawa, and H. Kojima (2004), The global accretion rate of extraterrestrial materials in the last glacial period estimated from the abundance of micrometeorites in Antarctic glacier ice, Earth Planets Space, 56, 67-79.

Yada, T., T. Nakamura, T. Noguchi, N. Matsumoto, M. Kusakabe, H. Hiyagon, T. Ushikubo, N. Sugiura, H. Kojima, and N. Takaoka (2005), Oxygen isotopic and chemical compositions of cosmic spherules collected from the Antarctic ice sheet: Implications for their precursor, Geochim. Cosmochim. Acta, 69, 5789-5804.

Yiou, F., G. M. Raisbeck, D. Bourles, C. Lorius, and N. I. Barkov (1985), 10Be in ice at Vostok Antarctica during the last climatic cycle, Nature, 316, 616-617 


\section{Figure 1.}

875 The representative back-scattered electron image of different type of cosmic spherules 876 selected for the oxygen isotope studies: a) scoriaceous, b) porphyritic, c) barred, d) 877 cryptocrystalline, e) glass, f and g) CAT, along with h) I-type and i) G-type. The backscattered images scale bars indicates $50 \mu \mathrm{m}$. The detail bulk chemical compositions of the particles are given in Appendix A.

880

\section{Figure 2.}

882 The backscattered electron image of polished sections of the cosmic spherules with metal 883 bead where oxygen isotope analyses were performed on silicate. (a) SP005-P1078 is one porphyritic spherules that have two metal beads. (b) MS-I3-P59, (c) MS-I3-P39, and (d) SP005-P10 are glass spherules with the metal bead. (e) SP007-P4, (f) SP005-P1176 and (i) SP005-P207 is barred, cryptocrystalline and G-type with metal bead. (g) SP007-P255 and (h) AAS-62-61-P87 are CAT and I-type spherules have metal bead void formed either by the dissolution of the metal bead whilst on the seafloor or by plucking during the polishing process. The back-scattered images scale bars indicates $50 \mu \mathrm{m}$.

890

\section{Figure 3.}

892 The oxygen isotope compositions of cosmic spherules: a) porphyritic, b) barred, c) 893 cryptocrystalline, d) glass, e) I-type and f) G-type obtained using ion microprobe. The oxygen isotope data are given in Appendix A. The solid lines represents the terrestrial fractionation 

shown are smaller than the size of symbol.

898

\section{$899 \quad$ Figure 4.}

900 The oxygen isotope compositions of least altered and most altered cosmic spherules, 901 scoriaceous and CAT spherules analyzed using ion microprobe. The oxygen isotope data are given in Appendix A. The solid lines represents TF and CCAM line with slope 0.52 and 0.94, respectively (Clayton et al., 1977; Clayton and Mayeda, 1999). All error bars are small than the size of the symbol.

Figure 5.

907 Plot of $\Delta^{17} \mathrm{O}$ for different types of spherules analysed in this study. Most of the data are below 908 the TF line suggesting cosmic spherules are contributed by carbonaceous chondrites. 909 Conversely, I-type spherules are near the TF line. The number at the corner of each plot is the average value of the $\Delta^{17} \mathrm{O}$ along with error. All error bars shown are $2 \sigma$.

\section{$912 \quad$ Figure 6.}

(a) The plot of $\delta^{18} \mathrm{O}$ vs. magnetite rim thickness of I-type spherules appears to increase with $\delta^{18} \mathrm{O}$ values. (b) The plot of $\delta^{18} \mathrm{O}$ versus the diameter of I-type spherules with sizes less than $915300 \mu \mathrm{m}$ from this study. Results of I-type spherules data for both magnetite thickness and diameter from Engrand et al. (2005) have been included in the plot for comparison. The plots

917 indicate that with increase in $\delta^{18} \mathrm{O}$ values the magnetite rim and diameter of spherule range 918 also increases. The circle marked in $\mathrm{b}$ is the data seems anomalous and is slightly far from 919 the trend. 
$921 \quad$ Figure 7.

922 The variation of $\mathrm{Ni}(\mathrm{wt} \%)$ in metal bead and $\delta^{18} \mathrm{O}$ from different types (porphyritic, barred, 923 cryptocrystalline, glass, G-type) of spherules. Glass spherule has good statistics where we can 924 suggest increase trend in $\mathrm{Ni}$ content with respect to $\delta^{18} \mathrm{O}$. Other spherules do not have good statistical representation. Few particles excluded from this plot are MS-I3-P55 (glass), MSI35-P22 (glass), SP007-P255 (CAT) and AAS-62-61-P87 (I-type). They have shown void space due to removal of metal bead either by the dissolution of the metal bead during its residence time on seafloor, during sample polishing, or during atmospheric entry.

\section{Figure 8 .}

931 The behaviour of $\delta^{18} \mathrm{O}$ from different types (porphyritic, barred, cryptocrystalline, glass, Gtype) of spherules with respect to the diameter of the spherules. There seems to overall increase in $\delta^{18} \mathrm{O}$ values with the increase in diameter but not uniform probably due to complexity involved in entry parameter and precursor original oxygen isotope composition.

Figure 9.

937 Compiled oxygen isotopic compositions $\Delta^{17} \mathrm{O}$ vs. $\delta^{18} \mathrm{O}$ values of different types of cosmic spherules analyzed in this study using ion microprobe. The range of oxygen isotope composition of various chondritic parent bodies (such as $\mathrm{CI}, \mathrm{CM}, \mathrm{CV}, \mathrm{CO}, \mathrm{CK}, \mathrm{CR}, \mathrm{H}, \mathrm{L}$, LL, EC, and R) are illustrated (Clayton et al., 1991; Clayton and Mayeda, 1999). The shaded region is the value of the isotopic composition of the micrometeorite from the various

942 precursor. The different group 1, 2, 3, 4 with a diverse isotopic range of $\Delta^{17} \mathrm{O}$ and $\delta^{18} \mathrm{O}$ is 943 earlier defined by Suavet et al. (2010). 